\section{Como Fazer Corpos com Palavras?} Uma Reflexão Sobre a Produção Performativa de Identidades de Gênero

How to do Bodies with Words? A Reflection on Performative Production of Gender Identities

Marco Antonio Lima do Bonfim*, Claudiana Nogueira de Alencar ${ }^{*}$, José Ernandi Mendes ${ }^{* *}$

RESUMO: O presente artigo teve como objetivo discutir a relaçáo entre linguagem e corpo nos estudos da linguagem, refletindo sobre as implicações teóricas desta relação para os estudos relacionadosà produção de identidades de gênero. Para tanto, refletimos principalmente, sobre a teoria dos atos de fala (AUSTIN, 1990), nos trabalhos de Butler (1997, 1999, 2000, 2012) e Pinto $(2002,2007,2009)$ a respeito da estilização de gênero em linguagem, bem como no estudo de Silva (2005) sobre a construçáo performativa de identidades de gênero. Desta forma, pretendemos demonstrar que os estudos linguísticos que lidam com o tema da(s) identidade(s) devem considerar a relação inevitável entre corpo, linguagem e poder, sob pena de ficarem reféns de uma abordagem reducionista do uso linguístico.

PALAVRAS-CHAVE: Performatividade. Corpo. Identidades de gênero.

ABSTRACT: This article aims to discuss the relationship between language and body in language studies, reflecting on the theoretical implications of this relationship for studies related to the production of gender identities. To this end, we reflected mainly on the theory of speech acts (AUSTIN, 1990), Butler $(1997,1999,2000,2012)$ and Pinto's $(2002,2007,2009)$ work on gender stylization in language, as well as on Silva's (2005) study on the performative construction of gender identities. In this way, we intended to demonstrate that linguistic studies dealing with the theme of identity (s) must consider the inevitable relationship between body, language and power, otherwise they will be held hostage to a reductionist approach to linguistic use.

KEYWORDS: Performativity. Body. Gender identities.

\section{Linguagęm Foco \\ Revista do Programa de Pós-Graduação em Linguística Aplicada da UECE}

Bolsista de Pós-doutorado (PNPD-CAPES) no Mestrado Acadêmico Intercampi em Educação da Universidade Estadual do Ceará, UECE, doutor e mestre em Linguística Aplicada pelo Programa de Pós-Graduação em Linguística Aplicada (POSLA) e professor do Mestrado Acadêmico Interdisciplinar em História e Letras (MIHL - UECE) orientando pesquisas de mestrado na linha de pesquisa Gênero, Raça e Identidades. E-mail: marco.bonfim@uece.br

Doutora em Linguística, na área de Semântica/ Pragmática, pela Universidade Estadual de Campinas, UNICAMP. Professora do Curso de Letras da Universidade Estadual do Ceará (UECE), no Programa de Pós-Graduação em Linguística Aplicada (POSLA) e no Mestrado em Educação e Ensino (MAIE) da UECE. E-mail: claudiana.alencar@uece.br

** Doutor em Educação Brasileira pela Universidade Federal do Ceará. Professor do Mestrado Acadêmico Intercampi em Educaçáo e Ensino - MAIE na Universidade Estadual do Ceará - UECE. E-mail: ernandi. mendes@uece.br

d. $10.46230 / 2674-8266-11-2921$

Distribuído sob

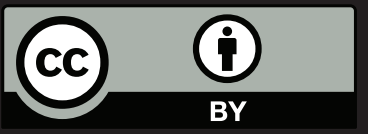




\section{INTRODUÇÁO}

Há algumas décadas que várias pesquisas na área da Linguística e da Filosofia da linguagem, partindo de releituras da Teoria dos Atos de Fala do filósofo inglês J. L. Austin vêm postulando um campo de estudo que reflete sobre a relação entre corpo, linguagem e relações de poder que regulam e constrangem a produção de nossas subjetividades. Tais interpretações discutem o corpo como ato de fala ou os processos corporais de subjetivação como performativos. Segundo Pinto (2009, p. 3), a fim de investigar o lugar do corpo como ato de fala "autoras e autores diversos exploram, direta ou indiretamente, o pensamento austianiano." Entre as autoras, temos a filósofa americana Judith Butler, que, com diversas pesquisas, tem radicalizado a tese central de Austin de que a linguagem é performativa.

No Brasil, tendo por base as releituras feitas por Rajagopalan (1989; 1990; 1992a; 1996a; 1996b; 2000a; 2000c) e Derrida (1990) sobre a teoria dos atos de fala austiniana (Austin, 1976; 1998), e a teoria de gênero elaborada por Butler (1997; 1999), a linguista Joana Plaza Pinto (2002, p.17) propóe "uma discussão sobre como o discurso sobre linguagem, sendo performativo, opera as estilizaçôes de gênero, postulando identidades", isto é, propõe estudar não as representações de gênero no discurso, mas a forma como nossos dizeres (atos de fala) operam estilizaçóes de gênero marcando nossos corpos como "mulher", "homem", "bicha" etc.

Fundamentados nestas discussóes é que propomos, neste artigo, discutir a relação entre linguagem e corpo nos estudos da linguagem, refletindo sobre as implicaçôes teóricas desta relação para os estudos relacionados à produção de identidades de gênero. Para tanto, na primeira seção, retomamos a Teoria dos Atos de Fala austiniana na sua relaçáo com possíveis pesquisas sobre performatividade e corpo. $\mathrm{Na}$ segunda, discutimos que nossas identidades sociais resultam dos efeitos perlocucionários de nossas interaçôes linguísticas nas mais diversas situações sociais, relacionando este debate a respeito da noção de identidade performativa com a noção de (identidade de) gênero. Por fim, na terceira seção, apresentamos a noção de estilizaçôes de gênero através da relação inevitável entre linguagem e poder na (trans)formação de identidades.

Esperamos que esta reflexão possa demonstrar a importância das pesquisas sobre o corpo nos estudos linguísticos - que focalizam a produção social de identidades - no Brasil, onde segundo Pinto (2009, p. 10), “o corpo é freqüentemente negligenciado ou patologizado pelos estudos da linguagem”.

\section{PERFORMATIVIDADE E CORPO}

É de conhecimento de todos/as interessados/as nos estudos da linguagem, principalmente os/ as pesquisadores/as ligados à Pragmática, discussão que J.L Austin ([1976]1990) empreendeu sobre os enunciados performativos, isto é, enunciados que operam uma ação. Tal discussão partiu da inquietação de Austin no que se refere à maneira como a linguagem era entendida pelos filósofos e linguistas de sua época ${ }^{1}$.

Para estes, os processos de significação eram realizados através da correspondência entre as palavras (linguagem) e os objetos, que teriam por função apresentar de novo aquilo que já estava construído em

\begin{tabular}{c|c|c|c}
\hline Revista Linguagem em Foco & Fortaleza, CE & v. 11 n. 2 & ISSN 2674-8266 \\
\hline
\end{tabular}


algum lugar fora da linguagem, isto é, de refletir a "essência" das coisas (representacionismo linguístico).

Discordando desta postura, Austin (1990, p. 26) questiona: "Pode o dizer realizar um ato?” Ou seja, será que para além de representarmos algo, nós fazemos alguma coisa com palavras? Buscando, portanto, refletir sobre "quando dizer é fazer", Austin propõe, inicialmente, uma distinção entre enunciados que "dizem"/representam coisas (constatativos) e os enunciados que "fazem" coisas (performativos).

O referido filósofo, a princípio, quis mostrar que ao dizer algo nós não só dizemos, mas fazemos este algo. Vejamos alguns exemplos:

1. digo sim no casamento ao juiz ou ao padre;

2. batizo um navio com nome de "Titanic" ao quebrar uma garrafa no casco do navio;

3. deixo meu relógio para meu irmão como parte de meu testamento

4. aposto cinco reais que amanhã chove.

Para estudar as açôes executadas pelos enunciados performativos, Austin propóe uma reflexão sobre os Atos de Fala. Nesta, sustenta que dizer algo é realizar três atos no mesmo enunciado: um ato locucionário - ato de "dizer algo" (fonemas, palavras), um ato ilocucionário - realização de uma ação ao dizer algo (força exercida pelo ato de dizer algo) e um ato perlocucionário - realização de uma ação por dizer algo (consequências/efeitos do dizer). Exemplificando: di Tais proferimentos não descrevem fatos, mas os constituem, são a própria ação em andamento; Quando digo, por exemplo, "atire nela!", estou executando uma ordem, não importa aqui se essa sentença é verdadeira ou falsa (como queriam os filósofos tradicionais), mas sob que condições esta ação se realiza ou não. gamos que por ocasião de um assalto um cidadão diga essa frase - Cuidado! Ele vai atirar - é um ato locucionário; que este cidadão, por meio dessa expressáo linguística, faça uma advertência, isso é o ato ilocucionário; que por meio dessa expressão, o sujeito consiga alertar alguém do disparo, isso é o ato perlocucionário. Note que "os três atos são realizados por meio da mesma expressão linguística, o que manifesta que não se trata de três atos distintos, mas de três dimensóes do mesmo ato de fala" (OLIVEIRA, 2006, p. 160).

Contudo, para que possamos praticar uma ação na e através da linguagem, Austin (1990, p. 30) nos esclarece que "[a]lém do proferimento das palavras chamadas performativas, muitas outras coisas em geral têm que ocorrer de modo adequado para podermos dizer que realizamos, com êxito, a nossa ação.” Isto é, para que os atos possam ser executados são necessárias certas condições sociais, uma vez que as açôes são executadas na medida em que seguem um conjunto de regras intersubjetivamente estabelecidas e aceitas pelos/as próprios/as usuários/as da linguagem ${ }^{2}$.

Desta forma, Austin conclui, portanto, que "[...] o performativo realiza uma ação através de um enunciado, que é a realização de um ato de fala [...]" (OTTONI, 1998, p. 36). Após esta "constatação"

2 Pinto (2007, p. 24), sintetiza bem as condições para a execução de um performativo. "São seis as condições para o funcionamento regular ou 'feliz' de um performativo, que podem ser traduzidas livremente como: A.1) a existência de procedimentos convencionais aceitos para enunciar certas palavras por certas pessoas em certas circunstâncias; A.2) pessoas e circunstâncias devem ser apropriadas para o procedimento invocado; B.1) o procedimento deve ser executado corretamente; B.2) e completamente; Г.1) os procedimentos devem ser usados por pessoas com certos pensamentos ou sentimentos, ou intenção de conduta; Г.2) e tais pessoas devem realmente conduzir-se de acordo com a conduta intencionada. (Austin 1976:14-15).” 
podemos dizer que sua argumentação vai caminhando para enfim, desaguar em uma "visão performativa da linguagem”. Pois, se todo ato de fala não só realiza uma ação, como é a própria ação, a distinção proposta por Austin, no início de suas conferências ${ }^{3}$ entre enunciados constatativos e performativos, que pretendia (diga-se taticamente) distinguir entre dizer e fazer, não mais se sustenta. "Pois o constatar [...] é um ato ilocucionário como qualquer outro, de modo que quando se faz uma constatação executa-se um ato ilocucionário semelhante a ameaçar, advertir, protestar, prometer etc. [...]” (OLIVEIRA, 2006, p. 162-163).

Avançando em suas considerações sobre a tripartição do ato de fala procurando focalizar a "força ilocucionária” em seu debate de que "todo dizer é um fazer", Austin propóe, na IX Conferência, mais uma distinção: "Devemos distinguir o ato ilocucionário do ato perlocucionário. Por exemplo, devemos distinguir entre 'ao dizer tal coisa eu o estava prevenindo' e 'por dizer tal coisa eu o convenci, ou surpreendi, ou o fiz parar" (AUSTIN, 1990, p. 96).

O que interessa destacar deste momento da reflexão austiniana, é a argumentação de Austin a respeito da relação entre ação e efeito, tendo por base a separação entre ação real mínima ("ação real no mínimo sentido físico suposto") e suas consequências. Por exemplo, "dobrar um dedo, que acionará um gatilho, que resultará na morte do burro” (AUSTIN, 1990, p. 97). Neste exemplo, Austin abre precedentes para uma reflexão entre corpo e linguagem, pois esta ação mínima real (dobrar o dedo...) é parte integrante da realização de um ato de fala. Ou seja, "[o] que faz do ato de fala uma ação está redobrado pela força da ilocução e pela força do movimento, do agir do corpo que executa a ilocução" (PINTO, 2007, p. 10).

Continua a autora,

Assim, a presença material e simbólica do corpo na execução do ato é uma marca que se impóe no efeito lingüístico. Uma ameaça se materializa pelo enunciado performativo que a opera, mas também pelo efeito do movimento do corpo que executa o enunciado. Essa afirmaçáo náo cria, como se poderia esperar, uma dicotomia corpo/linguagem, mas, ao contrário, mostra que o efeito do ato de fala é operado ao mesmo tempo pelo que é dito, pelo quem diz e pelo como é dito - como o corpo diz, como o enunciado diz. (PINTO, 2007, p. 10).

Austin, na verdade, já estava apontando para o que atualmente é designado como "estudos do corpo" na linguagem (PINTO, 2009), quando comentou: “[...] o divórcio entre açôes 'físicas' e atos de dizer algo não é de todo completo - há alguma vinculação." (AUSTIN, 1990, p. 98). Dito de outra forma, não fazemos apenas com palavras, mas também com o corpo. Tal postulação nos conduz a seguinte indagação: Se tudo que dizemos faz, será que fazemos corpos/identidades com linguagem?

\section{IDENTIDADE PERFORMATIVA E GÊNERO}

Ao concebermos linguagem e corpo de forma integrada na execução do ato de fala, estamos discutindo o ato de fala como um ato corporal. Nesse sentido, o debate sobre a performatividade deve ser feito levando em conta nossa existência discursiva, ou seja, nossas identidades. Hall (2000, p. 109) 3 A chamada "Teoria dos Atos de Fala" teve a sua semente plantada a partir das doze conferências ministradas por Austin na Universidade de Harvard (EUA), em 1955, que foram publicadas postumamente em 1962, com o título "How to do things with words", traduzido para o português como "Quando dizer é fazer: palavras e ação".

\begin{tabular}{c|c|c|c}
\hline Revista Linguagem em Foco & Fortaleza, CE & v. 11 n. 2 & ISSN 2674-8266 \\
\hline
\end{tabular}


argumenta que as questóes relativas às nossas identidades têm a ver com “quem nós podemos nos tornar', 'como nós temos sido representados' e 'como essa representação afeta a forma como nós podemos representar a nós próprios"”. Se nossas identidades se relacionam com a "representação" (construção) que o outro faz de nós, e como esse processo se dá linguisticamente, a partir das consequências produzidas pelo nosso dizer (efeitos perlocucionários), podemos pensar que as nossas identidades são construídas performativamente, isto é, como já disse um dos autores em outro trabalho (BONFIM, 2015, p. 98), "somos sempre efeitos, tanto de nossos como de outros atos de fala, que reiteradamente postulam o que nós estamos sendo". Nossas performances identitárias resultam, portanto, dos efeitos perlocucionários de nossas (inter)açóes sociais praticadas no dia a dia. Assim, é que, por exemplo, temos as "identidades de gênero": "mulher", "homem”, "gay”, "travesti”, "lésbica”, etc.

Da perspectiva dos atos de fala, "[i]dentidades são construçôes exigidas pelos ritos convencionais que postulam o sujeito de maneira a garantir a possibilidade do 'nós' a partir da significaçáo da existência prévia do 'eu' (PINTO, 2002, p. 93). Seguindo este raciocínio é que às vezes escutamos enunciados como "lugar de mulher é na cozinha", "macho que é macho bebe cachaça e não faz careta" ou "Bicha, cara, bicha fala demais, cara!" (PINTO, 2002, p. 196). Tais atos de fala nos remetem ao debate sobre o conceito de gênero social.

Conforme Silva (2005, p. 94), esta categoria "está profundamente relacionada ao desenvolvimento do feminismo norte-americano, a partir da década de 1960, em seu íntimo diálogo com o pós-modernismo francês." Ainda segundo o referido autor, é de interesse do movimento feminista compreender como o sujeito "mulher" se relaciona com o sujeito "homem", no que diz respeito à construção cultural de hierarquias e de dominaçôes. Nesse sentido, uma tese cara não apenas para este movimento social, mas também para outros como o movimento negro, de homossexuais, entre outros, é que a dominação e a desigualdade (social, econômica, sexual) impostas pelo centro hegemônico [branco, masculino e heterossexual] não são naturais, mas naturalizadas. Portanto,

[...] os estudos de gênero têm procurado acentuar o caráter social das diferenças ditas sexuais, e expor a relaçáo entre os gêneros como uma complexa rede de poderes, naturalizados e levados bem além do biológico pela distinçáo entre feminino e masculino, e ao mesmo tempo fragmentados pelas repetiçôes, modificaçôes e recusas da incessante constituição das identidades de gênero. (PINTO, 2002, p. 20).

Dito isto, percebemos que os atos de fala "lugar de mulher é na cozinha", "macho que é macho bebe cachaça e não faz careta" e "Bicha, cara, bicha fala demais, cara!" instituem "representações de gênero" no uso cotidiano da linguagem entre sujeitos situados sócio-historicamente.

Na próxima seção, discutiremos que tais representaçôes em uma concepção radical da teoria dos atos de fala são estilizaçôes de gênero construídas performativamente em situações concretas de conversação (PINTO, 2002). 


\section{ESTILIZAÇÓES DE GÊNERO: LINGUAGEM E PODER NA (TRANS)FORMAÇÁO DE} IDENTIDADES

Como vimos acima, a partir dos estudos e dos movimentos feministas, a compreensão de que a palavra "gênero" tem a significação de uma "marca cultural de corpos sexuados naturais" (SILVA, 2005, p. 97) foi descartada, ficando em seu lugar uma concepção que a entende enquanto uma construçáo social. Isto é, identidades de gênero são forjadas em meio às relaçôes de poder ${ }^{4}$ vivenciadas, por exemplo, pelos corpos nomeados "mulher", "homem”, "gay”, nas várias situações de interaçôes sociais.

No que diz respeito à construção deste tipo de identidade, Pinto (2007, p. 4) defende que "gênero" é um efeito de atos de fala, "cuja violência está em se apresentarem como reais, naturais, produzindo uma estrutura sempre binária [homem/mulher] e hierarquizada”, operando o que ela denomina de estilizaçóes de gênero em oposição a representações, uma vez que tais estilizações são performativas. Diz ela:

Se gênero é um efeito do ato de fala, ele deve ser entendido no conjunto do ato corporal porque o sujeito está totalmente implicado nas regras discursivas que possibilitam o corpo. Como ser se não ou 'homem' ou 'mulher'? Essa primeira regra opera a heterossexualidade compulsória, e postula a única possibilidade do sujeito (PINTO, 2007, p. 20).

Com base nas releituras feitas por Rajagopalan (1989; 1990; 1992a; 1996a; 1996b; 2000a; 2000c) e Derrida (1990) sobre a teoria dos atos de fala austiniana (AUSTIN, 1976, 1998), e na teoria de gênero elaborada por Butler (1997; 1999), a referida linguista propóe "uma discussão sobre como o discurso sobre linguagem, sendo performativo, opera as estilizaçôes de gênero, postulando identidades" (PINTO, 2002, p. 17). Para tanto, a autora buscou compreender os aspectos linguísticos na regulaçáo dos corpos, ou, com outras palavras, os processos corporais de subjetivaçáo como performativos. E o que são estilizaçôes de gênero?

Pinto (2002) argumenta que o uso do termo "estilização" permite abordar não "o problema das 'coisas' que estão representadas nas expressôes lingüísticas" (PINTO, 2002, p. 19), mas "os atos que são realizados pelo corpo que fala no estabelecimento, criação, recriação e eventual subversão das relações de poder" (PINTO, 2002, p. 19). Segundo a linguista, estilização é, portanto, a produção de repetições de normas sociais rígidas para convencionar práticas e comportamentos sociais. Tal quadro normativo se manifesta na materialidade do ato de fala, que por sua vez, constitui nossas identidades sociais.

Nesse sentido, questiona a autora: "O que são identidades, se identidades não podem ser 'encontradas' na linguagem”? (PINTO, 2007, p. 14), uma vez que elas não são refletidas, mas performadas no uso diário da linguagem por sujeitos sociais. E continua, defendendo que "[do] ponto de vista dos atos de fala, identidades são performativas, ou seja, são efeitos de atos que impulsionam marcações em quadros de comportamentos (fala, escrita, vestimentas, alimentação, cultos, elos parentais, filiações, etc.)" (PINTO, 2007, p. 14).

Assim - seguindo o raciocínio da pesquisadora - argumentamos que o gênero resulta de um efeito de atos de fala, estamos dizendo que atos de fala operam estilizaçóes, e uma delas é a de gênero. Ou seja, a marca de gênero. No entanto, como já dissemos, o ato de fala é também um ato corporal. O que nos mostra que a relação entre performatividade, corpo e identidades reside nas relaçóes de poder emergidas 
na e pela situação concreta de conversação. Sustentar a tese de que o ato de fala é um ato executado pelo corpo (que fala) é entender que a presença material e simbólica do corpo no dizer (ato de fala) é uma marca que se impóe no efeito linguístico. Isto porque o corpo participa das relaçóes de poder simbólicas que o envolvem, pois nele estão inscritas as regulaçóes sociais como parte dessas estruturas de poder societal. Assim sendo, compreendemos que as estilizações impostas ao corpo integram os processos de marcação social, imputando as estilizaçôes de gênero, classe, raça, por exemplo, aos corpos nomeados "homem", "mulher", "gay".

Portanto, ao entender que o corpo que executa um ato de fala é fruto das ritualizaçóes sociais de poder nele inscritas, podemos perceber que o debate sobre a produção discursiva de identidades de gênero demanda uma série de outras questóes. Tomemos esta reflexão de Louro (2000), onde ela nos diz que:

\begin{abstract}
Nossos corpos constituem-se na referência que ancora, por força, a identidade. E, aparentemente, o corpo é inequívoco, evidente por si; em conseqüência, esperamos que o corpo dite a identidade, sem ambigüidades nem inconstância. Aparentemente se deduz uma identidade de gênero, sexual ou étnica de "marcas" biológicas; o processo é, no entanto, muito mais complexo e essa dedução pode ser (e muitas vezes é) equivocada. Os corpos sáo significados pela cultura e, continuamente, por ela alterados. Talvez devêssemos nos perguntar, antes de tudo, como determinada característica passou a ser reconhecida (passou a ser significada) como uma "marca" definidora da identidade; perguntar, também, quais os significados que, nesse momento e nessa cultura, estáo sendo atribuídos a tal marca ou a tal aparência. (LOURO, 2000, p. 8 - grifos nossos).
\end{abstract}

Nessa mesma direção, Butler (2000, p. 111) nos diz que "a materialidade do corpo não pode ser pensada separadamente da materialização daquela norma regulatória" já discutida neste texto. Ou seja, a discussão sobre a construção discursiva do gênero não deve ser travada simplesmente na oposição "gênero" X “sexo” (anatomia), uma vez que a própria ideia de "sexo" é também um efeito de atos de fala.

\begin{abstract}
Nesse sentido, o que constitui a fixidez do corpo, seus contornos, seus movimentos, será plenamente material, mas a materialidade será repensada como o efeito do poder, como o efeito mais produtivo do poder. Não se pode, de forma alguma, conceber o gênero como um constructo cultural que é simplesmente imposto sobre a superfície da matéria - quer se entenda essa como o "corpo", quer como um suposto sexo. Ao invés disso, uma vez que o próprio "sexo" seja compreendido em sua normatividade, a materialidade do corpo náo pode ser pensada separadamente da materialização daquela norma regulatória. O "sexo" é, pois, não simplesmente aquilo que alguém tem ou uma descrição estática daquilo que alguém é: ele é uma das normas pelas quais o "alguém" simplesmente se torna viável, é aquilo que qualifica um corpo para a vida no interior do domínio da inteligibilidade cultural. (BUTLER, 2000, p. 111, grifos nossos).
\end{abstract}

O que Butler (2012) quer mostrar é que a categoria "sexo" não é dada, nem tampouco prédiscursiva, ela tem uma história e esta história se confunde com a da manutenção da heterossexualidade compulsória, ou seja, para ela o que entendemos por "sexo" (no sentido de masculino e feminino) não é algo natural, mas naturalizado, construído discursivamente. Sua argumentação se desenvolve na esteira de um rompimento com o sistema binário dos gêneros, isto é, da forma de pensar que o corpo só pode ser masculino ou feminino.

Tal forma de pensar a ligação entre estes termos (masculino e feminino) apresenta a ideia de uma relação meramente mimética entre gênero e sexo, de tal forma que o primeiro refletiria o segundo ou seria por ele restrito. A recusa da tese da natureza do corpo nos conduz a ideia de que o próprio discurso da 
nossa natureza corporal é ele mesmo performativo. O "sexo" é na verdade parte de uma prática regulatória (o discurso heterossexualizante) que regula e constrange os corpos que produz através do ato da nomeação.

Butler (1997) cita o caso da interpelaçáo médica como exemplo, pois através do procedimento da ultrassonografia transforma-se o bebê em "ele" ou "ela" antes mesmo dele nascer, através do enunciado performativo: "é uma menina!" (ato de nomeação). Desta forma, o corpo "menina" é feminizado e inserido nos domínios inteligíveis da linguagem e de seu parentesco através da determinação do seu sexo. Como diz a própria autora, "o 'sexo' denota um regime, [...] uma linguagem que forma a percepção, modelando a força as inter-relaçôes pelas quais os corpos físicos são percebidos. Existe um corpo 'físico' anterior ao corpo percebido?” (BUTLER, 2012, p. 166).

Pelo que estamos percebendo as normas regulatórias do sexo trabalham discursivamente para constituir a materialidade dos corpos, de forma mais específica, do sexo do corpo materializando a diferença sexual a favor da naturalização da ordem heteronormativa. Por matéria (ou materialização) entenda-se o "processo de materialização que se estabiliza ao longo do tempo para produzir o efeito de fronteira, de fixidez e de superfície - daquilo que nós chamamos matéria [dos corpos]" (BUTLER, 2001, p. 163).

A materialização do sexo em um corpo é, portanto, uma imposição social por meio de normas que buscam regular e controlar corpos e subjetividades. Tais normas regulatórias precisam ser constantemente citadas para que a materialidade do sexo e do corpo seja garantida. É aqui que entra a dimensão performativa da linguagem, pois, estas normas são reiteradas nos discursos que circula(ra)m no meio social performando corpos.

É neste momento que entra em cena o diálogo com a performatividade inerente à linguagem discutida por J.L. Austin e relida aqui por Butler. Performatividade para Butler é a capacidade que a linguagem tem de "iteravelmente, isto é, outra vez [iter] e para o outro [itera]" (SILVA, 2005, p.46) produzir os efeitos que a própria linguagem nomeia. A performatividade "é sempre uma reiteração de uma norma ou conjunto de normas" (BUTLER, 2001, p.167).

Através dessa noção de performatividade é que Butler vai propor o gênero como efeito do discurso, ou seja, uma concepção do corpo como performance; como o efeito dos discursos produzidos sobre as significações da masculinidade e feminilidade. Nessa perspectiva não há como falar que o gênero é representado através, por exemplo, de palavras como "mulher", "travesti" e "homem", uma vez que "não há identidade de gênero por trás das expressôes do gênero; essa identidade é performativamente constituída, pelas próprias 'expressóes' tidas como seus resultados” (BUTLER, 2012, p. 48).

Portanto, aqui gênero não é algo que somos (no sentido de já nascermos mulher ou homem), mas algo que fazemos a todo o momento, uma performance. Tornar-se um sujeito feminino ou masculino implica uma série interminável de processos de reivindicação identitária que se manifestam em práticas discursivas.

Entender que o gênero é efeito de atos de fala é compreender que é o próprio ato de nomear um corpo, sua designação como mulher ou homem, feminino ou masculino, que produz este corpo. O corpo, portanto, tem uma importância central nesta discussão, pois, para Butler (2012, p. 59) "o gênero é a estilização repetida do corpo", ou melhor, o gênero surge como um efeito dos discursos que se organizam 
em torno do corpo. Um corpo vulnerável a linguagem, ao discurso, pois sua constituição se dá no interior de "uma estrutura reguladora altamente rígida" (o discurso da heterossexualidade compulsória) que se manifesta na materialidade do ato de fala, que por sua vez, constitui nossas identidades de gênero. Como atesta Butler (1999, p. 163), "discursos, na verdade, habitam corpos. Eles se acomodam em corpos; os corpos na verdade carregam discursos como parte de seu próprio sangue. E ninguém pode sobreviver sem, de alguma forma, ser carregado pelo discurso".

A partir do exposto podemos afirmar que 1) nosso dizer produz identidades, corpos; 2) no ato de fazer dizendo deve-se considerar a atuaçáo do corpo (tanto a anatomia como os discursos que a envolvem); 3) Gênero está implicado no poder, nas relaçôes de dominação; 4) O gênero, ou melhor, as estilizaçôes de gênero que marcam nossos corpos são um dos marcadores de diferenciação; e por fim, 5) Sendo estilizado no uso cotidiano da linguagem, o gênero não está "representado" nas expressóes "mulher", "homem" etc., mas na forma como estes dizeres agem na produção destas e de outras subjetividades.

\section{CONSIDERAÇÓES FINAIS}

Mas, afinal, que corpo é esse de que nos fala Butler? O corpo de Butler se entrelaça com o corpo de Joana Plaza Pinto? Seria ele a pele? A anatomia? Ou a forma como os discursos moldam socialmente esta anatomia? Seria ele feito e efeito pelo/do discurso? Seria ele a materialidade do ser?

No capítulo final de Problemas de gênero denominado "Inscrições corporais, subversóes performáticas” Butler problematiza o processo de materialização dos corpos através da percepção de que esta é remodelada como efeito de uma dinâmica do poder que se manifesta na construção do "sexo" como uma norma cultural que governa tal materialização e propõe a categoria "atos de gênero" como definindo "as várias maneiras como o corpo mostra ou produz sua significação" e sua relação com a forma como tal processo de atribuição de sentidos define o corpo. Pode-se concluir, então, que o gênero é uma estilização imposta ao corpo, uma marca. Butler (2012) chega até a usar a expressão "estilos de carne" para enfatizar essa ideia dos corpos como marcados pelo gênero.

A grande contribuição da discussão elaborada aqui é que esta reflexão faz avançar a ideia de que o corpo é investido politicamente na medida em que ele passa a ser cada vez mais entendido como efeito dos discursos que significam o corpo (anatomia). Desse modo, o corpo só toma corpo no discurso, na prática de linguagem.

\section{REFERÊNCIAS}

AUSTIN, J. L. How to do things with words. 2. ed. Oxford: Oxford University Press, 1976.

- Quando dizer é fazer: palavras e ação. Tradução de Danilo Marcondes de Souza Filho. Porto Alegre: Artes Médicas, 1990.

Performativo-constativo. In: OTTONI, Paulo Roberto. Visão performativa da linguagem. Campinas: Editora da UNICAMP, 1998. p. 107-144. (Viagens da Voz. Apêndice).

BONFIM, M. Dizendo e fazendo o Sem Terra assentado no MST-CE: rabiscos de uma pragmática 
etnográfica. Revista Passagens. Programa de Pós-Graduação em Comunicação da Universidade Federal do Ceará, v. 6, n.1, p. 93-113, 2015.

BUTLER, J. Excitable speech: a politics of the performative. New York: Routledge, 1997. . Como os corpos se tornam matéria: entrevista. Estudos feministas, Florianópolis, v. 7, n. 1-2, p. 155-167, 1999.

. Corpos que pesam: sobre os limites discursivos do sexo. In: LOURO, G. (Org.). O corpo educado: pedagogias da sexualidade. Traduçáo de Tomaz Tadeu da Silva. 2. ed. Belo Horizonte: Autêntica, 2000. p. 151-166.

- Problemas de gênero: feminismo e subversão da identidade. Tradução de Renato Aguiar. 4. ed. Rio de Janeiro: Civilização Brasileira, 2012.

DERRIDA, J. Limited Inc. Paris: Éditions Galilée, 1990.

HALL, S. Quem precisa de identidade? In: SILVA, T.T. Identidade e diferença: a perspectiva dos estudos culturais. Petrópolis, RJ: Vozes, 2000. p. 103-129.

LOURO, G. Pedagogias da sexualidade. In: LOURO, G. (Org.). O corpo educado: pedagogias da sexualidade. Tradução de Tomaz Tadeu da Silva. 2. ed. Belo Horizonte: Autêntica, 2000. p. 7-26.

OLIVEIRA, M. Reviravolta linguistico-pragmática na filosofia contemporânea. São Paulo: Ediçóes Loyola, 2006.

OTTONI, P. Visão performativa da linguagem. Campinas, SP: Editora da UNICAMP, 1998.

PINTO, J. Estilizaçôes de gênero em discurso sobre linguagem. 2002. Tese (Doutorado em Linguística) Instituto de Estudos da Linguagem, Universidade Estadual de Campinas, Campinas, SP, 2002.

. Conexôes teóricas entre performatividade, corpo e identidades. D.E.L.T.A., São Paulo, v. 23, n. $1,2007$.

. O corpo de uma teoria: marcos contemporâneos sobre os atos de fala. Cadernos Pagu, Campinas, v. 33, p.117-138, jul.-dez. 2009.

RAJAGOPALAN, K. Atos ilocucionários como jogos de linguagem. Estudos linguisticos, Lorena, n. 18, p. 523-530, 1989.

. Dos dizeres diversos em torno do fazer. D.E.L.T.A., São Paulo, v. 6, n. 2, p. 223-254, 1990.

. A irredutabilidade do ato ilocucionário como fator inibidor do êxito das tentativas taxonômicas.

D.E.L.T.A., São Paulo, v. 8, n. 1, p. 91-133, 1992a.

. O Austin do qual a Lingüística tomou conhecimento e a Lingüística com a qual Austin sonhou. Cadernos de estudos linguísticos, Campinas, n. 30, p. 105-116, 1996 a.

- A questão da referência e interpretação na teoria dos atos de fala. In: CASTRO, Maria Fausta Pereira de (Org.). O método e o dado no estudo da linguagem. Campinas: Editora da UNICAMP, $1996 \mathrm{~b}$.

. Linguistics, ideology and the ethical questions. [Campinas: s.n., 1997a]. [mimeo] 
O conceito de identidade em linguística: é chegada a hora de uma reconsideração radical? In: SIGNORINI, Inês (Org.). Lingua(gem) e identidade: elementos para uma discussão no campo aplicado. Campinas: Mercado das Letras, 1998a. p. 21-45. (Letramento, educação e sociedade).

A relevância social da lingüística. Estudos linguísticos, São Paulo, n. 29, p. 33-42, 2000 b.

. Austin's humorous style of philosophical discourse in light of Schrempp's interpretation of Oring's "incrongruity theory" of humour. Humor, v. 13, n. 3, p. 287-311, 2000c.

On Searle [on Austin] on language. Language \& communication, n. 20, p. 347-391, 2000a.

SILVA, D. Brahma Kumaris: a construção performativa de identidades de gênero. 2005. Dissertação (Mestrado em Linguística) - Instituto de Estudos da Linguagem, Universidade Estadual de Campinas, Campinas, 2005. 